\title{
THE EFFECT ON THE TRICHINELLA SKIN TEST OF SIMUL- TANEOUS INFECTION WITH BOVINE TUBERCULOSIS IN TRICHINOUS RABBITS ${ }^{1}$
}

\author{
BY GEORGE T. HARRELL AND NANCY J. HELSABECK \\ (From the Department of Medicine, Bowman Gray School of Medicine of Wake Forest \\ College, Winston-Salem)
}

(Received for publication August 5, 1946)

The possibility that infection with tuberculosis alters an individual's reactivity to trichinella antigen was suggested by the results of a survey on the incidence of trichinosis. It was noted that a higher percentage of positive reactions to trichinella antigen (18.3 per cent) was obtained in 674 patients with active tuberculosis in 3 sanatoria, than in 335 patients without tuberculosis (7.2 per cent) in 2 general hospitals (1). The explanation for this phenomenon has not been found by investigations on the possible effects of institutionalization and sensitization by the ingestion of nonviable trichinae $(2,3)$. The possibility of a biologic cross reaction, detectable by skin test, between Mycobacterium tuberculosis and Trichinella spiralis was investigated in guinea pigs infected simultaneously with tuberculosis and trichinosis (4). Because of the poor response of the guinea pig to trichinella skin test antigen, the possibility of such a cross reaction was neither confirmed nor denied, but it was found that guinea pigs infected simultaneously with both organisms showed heavier infections with $T$. spiralis than did similar animals suffering from trichinosis alone. The converse of this statement was not true, since the number of acid-fast organisms found on smears of the tuberculous lesions in trichinous guinea pigs was no greater than that observed in similar animals infected with $M y c o-$ bacterium tuberculosis alone. It was postulated that an increased density of infection with trichinae in patients with active tuberculosis might explain the higher incidence of positive trichinella skin tests in such patients.

The present experiments were undertaken in an attempt to discover whether a true biologic cross reaction detectable by skin test exists between Mycobacterium tuberculosis and Trichinella

1 This study was aided by a grant from the John and Mary R. Markle Foundation. spiralis. Since rabbits have been found to give better skin reactions to trichinella antigen than guinea pigs, this animal was selected for these experiments. This choice necessitated the use of a bovine strain of tubercle bacilli (2). Dogs have been found to give excellent skin reactions to trichinella antigen, but in preliminary experiments it was difficult to establish a uniform bovine tuberculous infection in them.

\section{MATERIALS}

Sixty rabbits of medium size were divided into 6 equal groups. The rabbits were between 4 and 9 weeks old, and weighed $21 / 4$ to $71 / 2$ pounds. They were fed a stock diet (Kasco Complete Rabbit Ration, Kasco Food Co. Cincinnati, Ohio) supplemented with green vegetables 3 times weekly. Each animal was kept in a separate cage, and the groups infected with tubercle bacilli were kept in a separate room from those infected with trichinae alone.

The strain of Trichinella spiralis used was obtained from the National Institute of Health and was carried in albino rats. The culture of Mycobacterium tuberculosis (bovine, Ravenel strain) was obtained from Dr. Florence Seibert of the Henry Phipps Institute of the University of Pennsylvania, and was carried on plain glycerol bouillon agar medium titrated to $\mathrm{pH}$ 7.4. This highly virulent strain has been used by Opie and Freund (5). Intravenous injections of $0.5 \mathrm{ml}$. of a suspension of 1 loopful of culture in $5 \mathrm{ml}$. of saline solution resulted in death of a rabbit within 24 days.

Part of the dried trichinella larvae used was furnished by Parke, Davis and Co., Detroit, Michigan; the remainder was recovered from infected rabbits in our own laboratory. For skin testing, a 1:200 weight/volume emulsion in normal saline was made with dried powdered larvae, and was allowed to stand for 4 hours at room temperature, and overnight in the refrigerator at $12^{\circ} \mathrm{C}$ The supernatant saline was then removed, placed in sterile rubber-stoppered vials, heated in a water bath at $60^{\circ} \mathrm{C}$. for 1 hour daily on 3 successive days, and tested for sterility (2).

Tuberculin prepared from bovine strains of tubercle bacilli was furnished by Sharpe and Dohme, Glenolden, Pennsylvania. Purified protein derivative (PPD) of human strains of tubercle bacilli, furnished by Dr. Seibert, was also used; rabbits infected with bovine strains of tubercle bacilli react to this material (6). 


\section{METHODS}

\section{Experiment 1: Skin tests}

Groups B and C were fed approximately 2 grams of meat which had been obtained from a rat heavily infected with trichinae 26 days previously. On the following day, groups $\mathrm{A}$ and $\mathrm{C}$ were injected in the groin with $0.1 \mathrm{ml}$. of a suspension of tubercle bacilli. ${ }^{2}$ Thirty-nine days after the injections, the abdomen of the animals was clipped, and skin tests were done with $0.1 \mathrm{ml}$. of a $1: 100$ dilution of tuberculin in distilled water, with $0.1 \mathrm{ml}$. of physiological saline solution containing $0.005 \mathrm{mgm}$. PPD, with $0.02 \mathrm{ml}$. of $1: 200$ trichinella antigen, and with 0.1 $\mathrm{ml}$. of saline solution as a control. The readings were made at 20 minutes, 24 hours, and 48 hours.

\section{Experiment 2: Intensity of trichinella infection}

Forty-five days after the injections, groups $\mathrm{A}$ and $\mathrm{C}$ were killed with a blow on the head; the rabbits in group B were killed 54 to 64 days after infection with trichinae. Three-tenths to 0.35 gram of muscle was removed from the right anterolateral aspect of the diaphragm, and from each of the right front and hind legs; 0.25 to 0.3 gram of intercostal muscle was removed. Because the degree of infection previously found in guinea pigs had varied so greatly between the group infected with both trichinosis and tuberculosis and the group infected with trichinosis alone, the samples were not accurately weighed, but were estimated (4). The tissues were examined in a muscle press using the $10 \times$ low power objective and $10 \times$ ocular lenses in the microscope. The absolute number of trichinae observed in each sample was recorded. Since the muscle press preparations on 2 animals (numbers 22 and 23 from group C) were negative, approximately 5 grams of muscle obtained from various sites in these animals was digested with 0.7 per cent pepsin and 1 per cent hydrochloric acid (7).

Groups $E$ and $F$ were fed 2 grams of trichinous rat meat, and the following day groups $D$ and $F$ were injected with $0.05 \mathrm{ml}$. of a $5 \mathrm{ml}$. suspension of tubercle bacilli prepared by the method described above. Two animals in group $E$ (numbers 13 and 16) were fed 7 days later than the remainder of the group, and their meat was prepared from a different rat. The animals were killed 70 to 86 days after infection, and the muscles examined in the manner described. Smears were made from tuberculous lesions in the lung, the liver, the regional lymph nodes, and at the site of injection in the groin. Smears were stained by the Ziehl-Neelsen technique, and the data recorded by the Gaffky scale.

2 The suspension was made from 1 medium-sized colony of a 6-weeks culture ground with 1 drop of sterile physiological saline in a small mortar. The suspension was subsequently diluted with saline to make the volume 10 $\mathrm{ml}$. and the large clumps were centrifuged out; the supernatant fluid showed 10 to 20 organisms per field with an oil-immersion lens.

\section{RESULTS}

One animal in group $\mathrm{C}$ died before the skin tests were done, and 2 animals in group $\mathrm{D}$ died of intercurrent disease before the experiments were completed. None of these animals is included in the results.

In 2 animals in group $C$ (numbers 22 and 23) no trichinae were found in any muscle press preparation, and digestion of muscle revealed no live trichinae. One animal from group B, 1 from group $E$, and 2 from group $F$ had very light infections, 1 to 3 trichinae being seen in muscle from 1 site only.

Each animal in groups A, C, D, and F presented gross evidence of tuberculosis at autopsy. In 1 animal from group $D$, and 1 from group $F$, smears of tuberculous lesions were negative; in all others acid-fast bacilli were found.

\section{Experiment 1: Skin tests}

No essential difference in reaction to the 2 trichinella antigens was noted (Table I). Twelve

TABLE I

Skin tests in trichinous and tuberculous rabbits

\begin{tabular}{c|c|c|c|c|c|c}
\hline \hline Group & $\begin{array}{c}\text { Num- } \\
\text { ber } \\
\text { ani- } \\
\text { mals }\end{array}$ & $\begin{array}{c}\text { Tuber- } \\
\text { culin }\end{array}$ & $\begin{array}{c}\text { Purified } \\
\text { protein } \\
\text { deriva- } \\
\text { tive }\end{array}$ & $\begin{array}{c}\text { Trichi- } \\
\text { nella } \\
\text { antigen } \\
\text { no. 1 }\end{array}$ & $\begin{array}{c}\text { Trichi- } \\
\text { nella } \\
\text { antigen } \\
\text { no. 2 }\end{array}$ & $\begin{array}{c}\text { Saline } \\
\text { con- } \\
\text { trol }\end{array}$ \\
\hline $\begin{array}{c}\text { A } \\
\text { (tuberculosis) }\end{array}$ & 10 & 3.2 & 3.5 & 0.1 & 0 & 0 \\
$\begin{array}{c}\text { B } \\
\text { (trichinosis) } \\
\begin{array}{c}\text { C } \\
\text { (tuberculosis } \\
\text { and trichinosis) }\end{array}\end{array}$ & 10 & 0 & 0.1 & 1.6 & 2.0 & 0 \\
\hline
\end{tabular}

The data are the arithmetic means of the scores of skin tests on a scale of 0 to 4 plus; doubtful ( \pm ) reactions are calculated as negative $(0)$.

Trichinella antigen no. 1 was prepared in our own laboratory; the larvae of antigen no. 2 were furnished by Parke, Davis and Co.

animals gave immediate positive skin reactions to trichinella antigen at 20 minutes; 11 animals gave 1 plus or greater reactions at 24 or 48 hours. Five animals, proved by muscle press preparations to be infected, gave negative skin reactions at all 3 periods to both antigens. One infected animal which failed to react at 20 minutes, gave a positive reaction at 24 hours, while 3 animals positive at 20 minutes failed to give reactions at 24 and 48 hours. One false positive reaction (1 plus) to a single trichinella antigen was encoun- 
tered in a tuberculous animal which had not been fed trichinae.

No difference in reactions to bovine tuberculin and human PPD was noted in the infected animals. None of the tuberculous animals gave immediate reactions to either antigen, and only 1 animal gave a 1 plus reaction; all of the other animals gave 3 or 4 plus tests. No false positive reaction to tuberculin or $\mathrm{PPD}$ was encountered in non-tuberculous animals.

\section{Experiment 2: Intensity of trichinella infection}

No essential difference in intensity of trichinous infections was found between groups $\mathrm{B}$ and $\mathrm{C}$, and between groups $E$ and $F$ (Table II). This

TABLE II

Density of trichinella infection of muscle

\begin{tabular}{|c|c|c|c|c|c|c|}
\hline Group & $\begin{array}{l}\text { Num- } \\
\text { ber } \\
\text { ani- } \\
\text { mals }\end{array}$ & $\begin{array}{c}\text { Dia- } \\
\text { phragm }\end{array}$ & $\begin{array}{l}\text { Inter- } \\
\text { costal }\end{array}$ & $\begin{array}{c}\text { Front } \\
\text { leg }\end{array}$ & $\underset{\text { leg }}{\text { Hind }}$ & $\underset{\text { sites }}{\text { All }}$ \\
\hline $\begin{array}{c}\underset{\text { B }}{\text { (trichinosis) }} \\
\text { C } \\
\text { (trichinosis } \\
\text { and } \\
\text { tuberculosis) }\end{array}$ & $\begin{array}{r}10 \\
9\end{array}$ & $\begin{array}{r}65.3 \\
42.9\end{array}$ & $\begin{array}{r}14.2 \\
4.2\end{array}$ & $\begin{array}{l}28.5 \\
12.1\end{array}$ & $\begin{array}{r}17.6 \\
5.9\end{array}$ & $\begin{array}{l}31.4 \\
16.3\end{array}$ \\
\hline $\begin{array}{c}\underset{\text { (trichinosis) }_{*}^{\mathbf{E}}}{\mathbf{F}^{\mathrm{F}}} \\
\underset{\text { (trichinosis }}{\text { and }} \\
\text { tuberculosis) }\end{array}$ & $\begin{array}{l}10 \\
(8) \\
10\end{array}$ & $\begin{array}{c}174.4 \\
(125.0) \\
114.0\end{array}$ & $\begin{array}{c}68.8 \\
(60.1) \\
43.7\end{array}$ & $\begin{array}{c}76.5 \\
(45.2) \\
42.2\end{array}$ & $\begin{array}{c}60.8 \\
(24.6) \\
15.7\end{array}$ & $\begin{array}{c}95.1 \\
(63.7) \\
53.9\end{array}$ \\
\hline
\end{tabular}

The data are the arithmetic means of the counts of larvae as seen in the muscle press. Groups $B$ and $C$ were fed on the same day, and groups $E$ and $F$ on another occasion.

* The data for group $E$ have also been calculated omitting rabiits number 13 and 16 which were fed from a more heavily infected rat 7 days later than the remainder of the group. These data are recorded in parentheses for more accurate comparison with group $F$.

was true for the counts of trichinae in muscle from any single site, as well as for all sites calculated together.

No difference in intensity of tuberculous infection was noted between groups $D$ and $F$ either in the number and extent of gross lesions, or in the number of organisms seen on smears of the lesions.

\section{DISCUSSION}

No biologic cross reaction between Mycobacterium tuberculosis and Trichinella spiralis was detected by skin tests in rabbits. Judged by the extent of positive reactions to the concentrations of antigens used, tuberculin and PPD are more specific for tuberculosis than is trichinella antigen for trichinosis. The failure of 4 animals with proved trichinosis to react to trichinella skin tests could not be accounted for either by overwhelming or by very light infections. Only 1 of these animals had a very light infection; the other 3 had infections which were average in density. A single animal gave an immediate false positive skin reaction to one trichinella antigen, though no trichinae had been fed to it.

The differences in reaction to trichinella antigen at 20 minutes, 24 hours and 48 hours are of interest in the light of experiments recently performed on dogs, using trichinella antigen digested with pepsin or trypsin, and presumably containing no reaginic protein (8). It is impossible at this time to say whether the immediate reactions at 20 minutes in rabbits are due to carbohydrate and the late reactions at 24 and 48 hours to protein, as the experiments in dogs might suggest.

Further experiments have been carried out in orphanage and prison groups, in order to compare the tuberculin and trichinella skin reactions in non-tuberculous, non-psychiatric institutionalized persons. These clinical experiments, which are being reported separately (3), confirm the animal experiments reported here; no biologic cross reaction seems to exist between the 2 infectious agents.

The experiments in rabbits infected simultaneously with bovine Mycobacterium tuberculosis and Trichinella spiralis reported here do not confirm the previously reported experiment in guinea pigs infected simultaneously with human Mycobacterium tuberculosis and Trichinella spiralis (4). The density of trichinous infection in rabbits simultaneously infected with trichinosis and tuberculosis was not found to be greater than that in rabbits infected with trichinosis alone.

\section{SUMMARY}

1. No biologic cross reaction was detected by skin tests in rabbits infected simultaneously with bovine Mycobacterium tuberculosis and Trichinella spiralis.

2. Simultaneous infection with bovine tuberculosis did not increase the intensity of trichinous infections in rabbits. 


\section{BIBLIOGRAPHY}

1. Harrell, G. T., and Horne, S. F., Trichinella skin tests in tuberculosis sanatoriums, hospitals for mental diseases, and general hospitals. Am. J. Trop. Med., 1945, 25, 51.

2. Avera, J. A., Yow, E. M., Harrell, G. T., and Fowler, E. B., An attempt by feeding to induce in animals reactivity to Trichinella spiralis in the absence of infection. Am. J. Trop. Med., 1946, 26, 125.

3. Harrell, G. T., Horne, S. F., Aikawa, J. K., and Helsabeck, N. J., Trichinella skin tests in an orphanage and prison: comparison with the flocculation test and with the tuberculin reaction. J. Clin. Invest., 1947, 26, 64.
4. Davis, O. T., Harrell, G. T., and King, E. S., The effect of simultaneous tuberculous infection on experimental trichinella infestations in guinea pigs. Am. J. M. Sc., 1945, 209, 758.

5. Opie, E. L., and Freund, J., Experimental study of protective inoculation with heat killed tubercle bacilli. J. Exper. Med., 1937, 66, 761.

6. Personal communication.

7. Bozicevich, J., Studies on trichinosis. XII. The preparation and use of an improved trichina antigen. Pub. Health Rep., 1938, 53, 2130.

8. Aikawa, J. K., Harrell, G. T., and Helsabeck, N. J., The effect of peptic and tryptic digestion on the antigenicity of Trichinella spiralis. J. Clin. Invest., 1947, 26, 73. 